\title{
SISTEM DETEKSI GLAUKOMA PADA FOTO FUNDUS RESOLUSI TINGGI
}

\author{
GLAUCOMA DETECTION SYSTEM ON HIGH RESOLUTION \\ FUNDUS \\ Hilman Fauzi ${ }^{1}$, Faidil Hadi ${ }^{2}$ \\ ${ }^{1,2}$ Peneliti, Jurusan Teknik Telekomunikasi, Fakultas Teknik Elektro, Universitas Telkom, \\ Jl. Telekomunikasi, Bandung 40257 Indonesia \\ 1' hilmanfauzitsp@telkomuniversity.ac.id, ${ }^{2}$ fay.hadi12@gmail.com
}

\begin{abstract}
Abstrak
Glaukoma adalah peradangan pada optic mata yang ditandai dengan kemunduran progresif dari kepala saraf optik dan luas pandang. Peradangan ini disebabkan oleh tidak seimbangnya proses produksi cairan dan pembuangannya pada bola mata sehingga menyebabkan tekanan cairan bola mata menjadi tinggi. Kemunduran progresif pada luas pandang bersifat permanen dan tidak dapat disembuhkan, sehingga pendeteksian dini sangat perlu dilakukan sebelum kerusakan menjadi semakin parah. Deteksi glaukoma dapat dilakukan dengan beragam cara, salah satunya adalah dengan melihat ukuran optik disk pada foto fundus digital. Namun, hasil identifikasi foto fundus secara manual dapat menghasilkan diagnosis yang kurang tepat. Pada penelitian ini dilakukan proses simulasi dan analisis suatu sistem yang dapat membantu praktisi kesehatan mendeteksi ukuran optik disk pada foto fundus sehingga dapat mendiagnosis dengan cepat dan akurat. Berdasarkan hasil dari simulasi, akurasi sistem mencapai $76 \%$ dengan waktu komputasi 1.5 detik.
\end{abstract}

Kata Kunci : glukoma, template matching, dilasi, erosi

\begin{abstract}
Glaucoma is an infection on optic characterized by a progressive degeneration of the optic nerve head and visual field defect. It is caused by an imbalance between the production and disposal of liquid in eyeball so that the intraocular pressure is increasing. Vision loss caused by Glaucoma is permanent and incurable. So, early detection is needed before the damage gets worse. Glaucoma detection can be done by various ways, such as measuring the size of disc in digital fundus images. But, the result of manual measurement can be less accurate. This final project will do a simulation and analysis of a system that can help ophthalmologist measuring the size of optic disc in digital fundus images and giving diagnose accurately in an instant. Methods used by this system including blurring, template matching, thresholding, dilate, and erode. Templates used by the system are old template that used in previous research and new template that has a better brightness than the old one. The results are the system has an accuracy up to $76 \%$ with computing time $1.5 \mathrm{~s}$. New template is able to cover the old template inability to detect the exact position of optic disc.
\end{abstract}

Keywords: glaucoma, template matching, dilate, erode 


\section{PENDAHULUAN}

Glaukoma adalah peradangan optik yang ditandai dengan kemunduran progresif dari kepala saraf optik dan luas pandang [1]. Peradangan ini disebabkan ketidakseimbangan produksi cairan dan pembuangannya dalam bola mata. Tekanan cairan bola mata terlalu tinggi, sehingga merusak serat lembut saraf optik yang membawa sinyal pengelihatan dari mata ke otak [2]. Dengan rusaknya serat lembut ini, menyebabkan luas pandang semakin berkurang dan bahkan bisa menyebabkan kebutaan. Data dari population-based surveys (PBS) mengindikasikan bahwa glaukoma adalah penyebab kebutaan nomor dua (setelah katarak), yaitu sebesar 8\% dari 36 juta penderita kebutaan di seluruh dunia [3]. Pada data lain, glaukoma disebutkan menjangkit 70 juta orang dan diperkirakan akan meningkat menjadi 79.6 juta orang di tahun 2020 [1].

Kerusakan serat lembut pada penderita glaukoma menyebabkan karakteristik optik disk berbeda dengan mata normal. Penderita glaukoma mengalami pelebaran pada optik disk, sehingga dapat menjadi tanda bahwa seseorang mengalami glaukoma. Glaukoma tak kasat mata sehingga sering tidak disadari. Kerusakan yang disebabkan oleh glaukoma tidak dapat diperbaiki. Pendeteksian dan penanganan lebih dini bisa mencegah penderita glaukoma mengalami kerusakan yang lebih parah [4]. Pada penelitian-penelitian sebelumnya, glaukoma dapat dideteksi dengan menggunakan sinyal laser, Optical Coherence Tomography (OCT), Heidelberg Retinal Tomography (HRT), pencitraan Biofotonik beresolusi tinggi, dan jaringan syaraf. Deteksi glaukoma dengan menggunakan Optical Coherence Tomography (OCT) dan Heidelberg Retinal Tomography (HRT) sangatlah mahal. Namun dengan menggunakan foto fundus digital dapat dideteksi dengan cepat dan lebih murah [5]. Lebih jauh, dengan menggunakan foto fundus digital dapat diketahui beragam tingkatan glaukoma [1].

Pada penelitian ini dilakukan proses simulasi dan analisis suatu sistem yang dapat mendeteksi glaukoma secara cepat. Input sistem berupa foto fundus digital yang diproses dan menghasilkan output berupa hasil diagnosis. Penelitian ini menggunakan metode template matching dengan menggunakan template dari penelitian lain dengan kemampuan deteksi optik mencapai 96\%[7].

\section{DASAR TEORI /MATERIAL DAN METODOLOGI/PERANCANGAN}

Sistem menggunakan template matching dan filtering untuk mendapatkan ciri dari tiap foto fundus kemudian dideteksi sebagai mata normal, glaukoma, dan tidak terdeteksi berdasarkan luas optik disk dengan menggunakan fungsi non-zero matrix.

\subsection{Glaukoma}

Glaukoma adalah peradangan optik yang ditandai dengan kemunduran progresif dari kepala saraf optik dan luas pandang [1]. Peradangan ini disebabkan ketidakseimbangan produksi cairan dan pembuangannya dalam bola mata. Tekanan cairan bola mata terlalu tinggi, sehingga merusak serat lembut saraf optik yang membawa sinyal pengelihatan dari mata ke otak [2]. Saraf optik yang sudah mengalami kerusakan parah akan mengakibatkan kebutaan. Berdasarkan gonioskopi, glaucoma dibedakan menjadi primary glaucoma dan secondary glaucoma. Primary glaucoma kemudian diklasifikasi sebagai Primary Open Angle Glaucoma (POAG) dan Primary Angle Closure Glaucoma (PACG) [9].

Pada bagian depan mata terdapat ruang yang disebut anterior chamber. Sebuah cairan bening mengalir terus menerus masuk dan keluar dari chamber dan memelihara jaringan di sekitarnya. Cairan meninggalkan ruangan di sudut terbuka di mana kornea dan iris bertemu. Ketika cairan mencapai sudut, mengalir melalui meshwork spons, seperti saluran pembuangan, dan meninggalkan mata [10]. Pada glaukoma sudut terbuka (POAG), meskipun sudut drainase terbuka, 
cairan mengalir terlalu lambat melalui saluran meshwork. Karena cairan menumpuk, tekanan di dalam mata naik ke tingkat yang dapat merusak saraf optik. Ketika saraf optik rusak dari peningkatan tekanan, glaukoma sudut terbuka bisa terjadi [10]. Pada glaucoma sudut tertutup (PACG), iris tidak lebar dan terbuka sebagaimana mestinya. Cairan tidak bisa keluar sehingga cairan menumpuk [11].

\subsection{Template Matching}

Pada penelitian ini metode yang digunakan adalah Template Matching, yaitu metode untuk mencari area suatu gambar yang tepat atau mirip dengan template image. Metode ini digunakan karena template matching sering dianggap sebagai dasar, pendekatan terbatas pada masalah yang paling menarik dari computer vision, menyentuh pada banyak teknik lama dan baru di bidangnya. Teknik ini terbagi dalam dua fitur umum. Pertama yaitu sistem bergantung pada template yang jelas, atau representasi dari gambar utuh sebenarnya. Kedua yaitu pengenalan dilakukan dengan pencocokan gambar yang ditetapkan sebagai template dengan gambar lainnya. Kemudian dibandingkan representasi citranya.

\subsection{Morfologi}

Morfologi merupakan salah satu teknik yang digunakan dalam pengolahan gambar biner. Kebanyakan algoritma morfologi adalah operasi logika sederhana. Setiap aplikasi membutuhkan solusi khusus yang dikembangkan dari trial-and-error. Cara ini lebih sering digunakan daripada algoritma standar dan sifat matematika formal.

Operasi morfologi yang digunakan adalah erosion dan dilation. Pada erosion, setiap objek pixel yang menyentuh background pixel berubah menjadi background pixel. Pada dilation, setiap background pixel yang menyentuh object pixel berubah menjadi object pixel. Erosion membuat suatu objek menjadi lebih kecil dan dapat membuat sebuah objek menjadi beberapa objek. Dilation membuat objek menjadi lebih besar dan dapat membuat beberapa objek menjadi sebuah objek.

\subsection{Blok Diagram Sistem}

Pada Gambar.1 digambarkan langkah - langkah yang dilakukan sistem agar dapat mengklasifikasikan citra uji yang masuk.

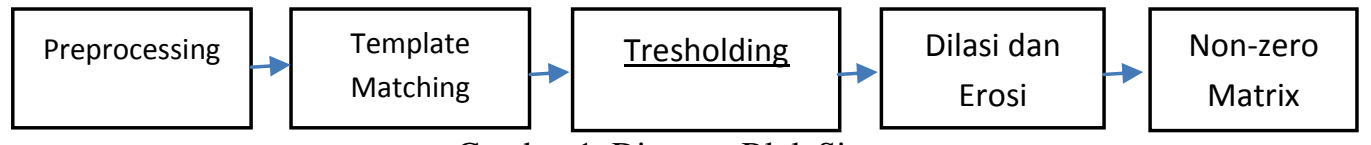

Gambar 1. Diagram Blok Sistem

Preprocessing merupakan tahap awal sistem, di tahap ini citra yang masuk dilakukan segmentasi optik disk. Untuk mendapatkan hasil yang baik dilakukan proses resize, pengambilan layer merah, dan blurring.

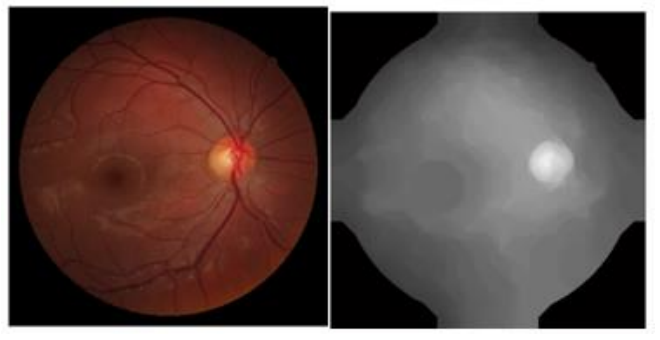

(a)

(b)

Gambar 2. Blurring untuk memperjelas optik disk

(a) Gambar original, (b) Hasil bluring dengan optikal disk yang tampak lebih jelas. 
Tahap selanjutnya merupakan tahap pendeteksian optik disk. Citra hasil dari preprocessing selanjutnya dilakukan proses template matching. Hasil dari template matching akan menunjukkan lokasi optik disk. Kemudian optik disk yang sudah tersegmentasi mengalami perubahan bentuk sehingga segmentasi optik disk menjadi lebih sempurna.

Hasil dari segmentasi yang lebih sempurna kemudian dihitung luasannya dengan nonzero matrix. Pengidentifikasian glaukoma dilakukan dengan membandingkan nilai dari nonzero matrix hasil segmentasi otomatis dengan nilai dari nonzeromatrix yang dilakukan secara manual oleh spesialis glaukoma.

\subsection{Pengujian}

Untuk mengetahui performansi dari sistem maka diperlukan tahap pengujian. Dalam pengujian ini akan dilakukan 3 tahap, yang pertama yaitu menguji akurasi sistem dalam mendeteksi optik disk, yang kedua yaitu menguji akurasi sistem untuk mendeteksi glaukoma, dan yang ketiga waktu komputasi sistem. Pada setiap pengujian, akan dilakukan perubahan pada nilai parameter yang telah ditentukan. Nilai yang diubah yaitu nilai kernel disk yang akan digunakan pada tahap blurring, nilai threshold untuk menentukan batas region optik disk, serta mengujicoba sistem dengan menggunakan dua template yang berbeda pada proses template matching.

\section{PEMBAHASAN}

Pada pembahasan ini akan dibagi menjadi dua bagian sesuai dengan skenario pengujian, yaitu akurasi segmentasi optik disk, akurasi deteksi glaukoma, dan waktu komputasi.

\subsection{Akurasi Segmentasi Optik Disk}

Dari pengujian yang dilakukan, dari 100 data yang diuji, mampu mendeteksi optik disk dengan akurasi sebesar 93\%.

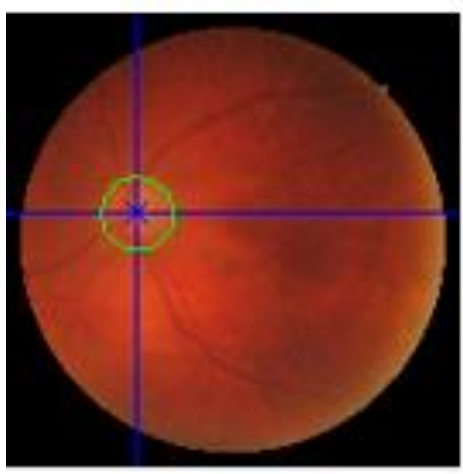

(a)

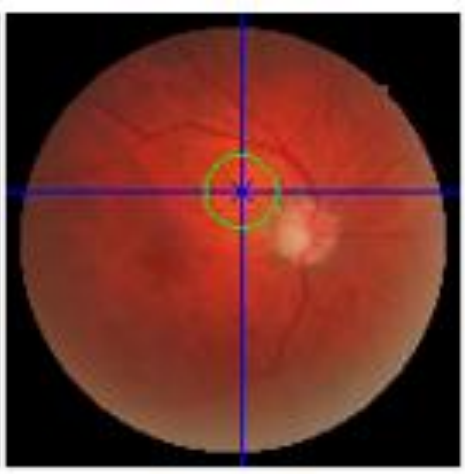

(b)

Gambar 3. Deteksi optik disk

(a) Fundus dapat mendeteksi optik disk, (b) Fundus tidak mampu mendeteksi optik disk

\subsection{Akurasi Deteksi Glaukoma}

Pada pembahasan ini akan dilakukan pengukuran tingkat akurasi deteksi glaucoma. Dalam melakukan pengukuran akurasi glukoma, dilakukan beberapa tahap pengujian sistem dalam mendeteksi glaucoma yaitu proses penentuan lokasi optik disk, konversi citra untuk segmentasi optik disk, dan penentuan luas optik disk sebagai penentu klasifikasi glukoma dan non-glukoma. 


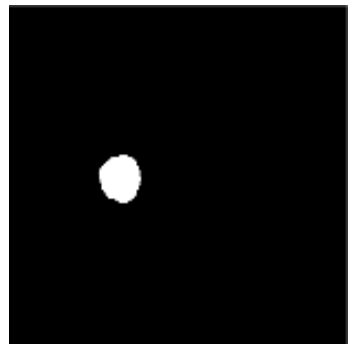

Gambar 4. ROI luasan optik disk dengan piksel berwarna putih

Pengukuran tingkat akurasi pendeteksian glukoma dilakukan dengan melakukan perbandingan antara segmentasi manual yang dilakukan oleh lima glaucoma domain experts dengan hasil segmentasi optik disk otomatis. Penentuan standar positif glukoma pada penelitianpenelitian sebelumnya dilakukan dengan menghitung rasio mangkok optik disk dengan optik disknya. Pada penelitian ini, penentuan standar positif glukoma dilakukan dengan menghitung luas optik disk pada citra (lihat gambar 3).

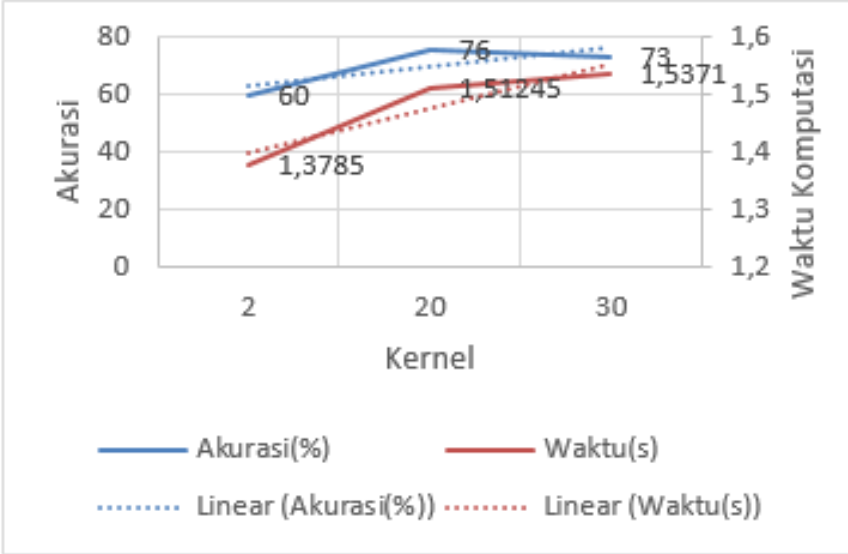

Gambar 5. Grafik hubungan kernel terhadap akurasi dan komputasitemplate lama

Berdasarkan grafik regresi linear Gambar.4, semakin besar kernel maka akan semakin meningkat akurasinya. Disisi lain, waktu komputasinya juga akan semakin lama. Efisiensi sistem dengan ukuran kernel yang kecil sangat tinggi. Akurasi tertinggi sebesar 76\% namun dengan waktu komputasi yang kurang efisien yaitu $1.51 \mathrm{~s}$.

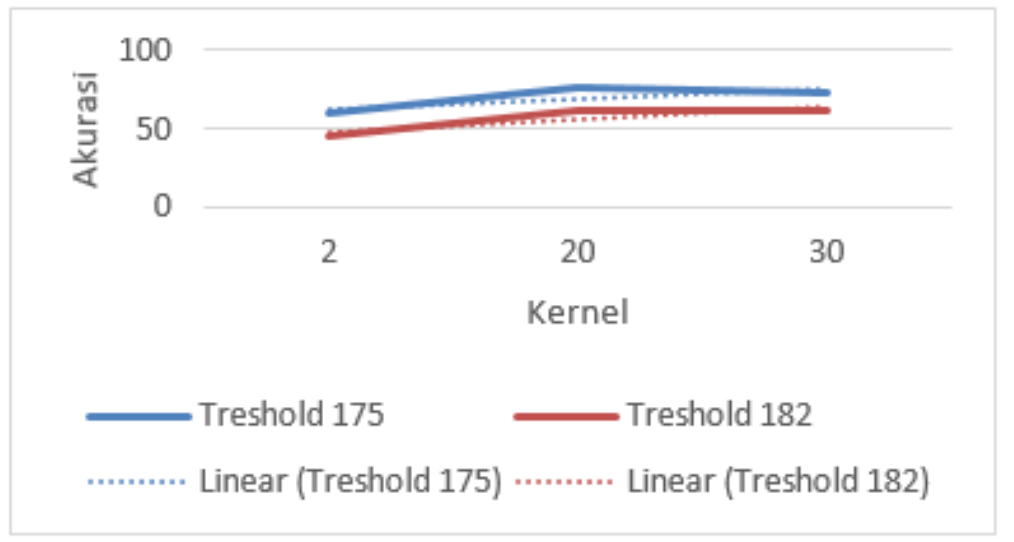

Gambar 6. Grafik hubungan kernel, akurasi, dan threshold 
Berdasarkan grafik Gambar 5, threshold dengan nilai lebih kecil akan memiliki akurasi yang lebih tinggi. Baik treshold 175 dan 182 menunjukkan kernel akan mempengaruhi tingkat akurasi. Semakin besar kernel, semakin besar tingkat akurasinya.

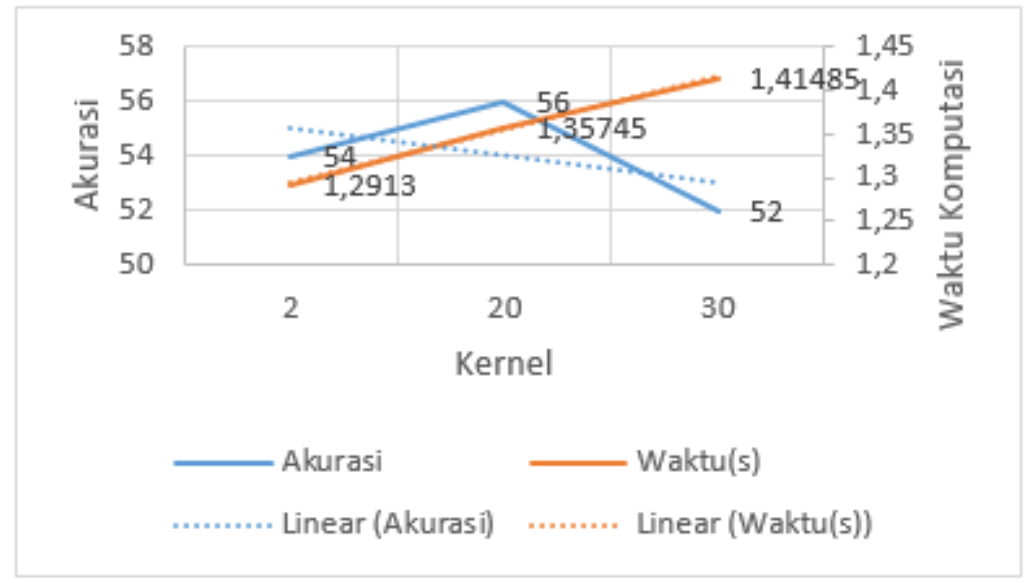

Gambar 7. Grafik hubungan kernel terhadap akurasi

Berdasarkan grafik regresi linear pada Gambar.6, semakin besar ukuran kernel justru semakin rendah akurasinya. Akurasi tertinggi sebesar 56\% dengan waktu komputasi $1.3 \mathrm{~s}$.

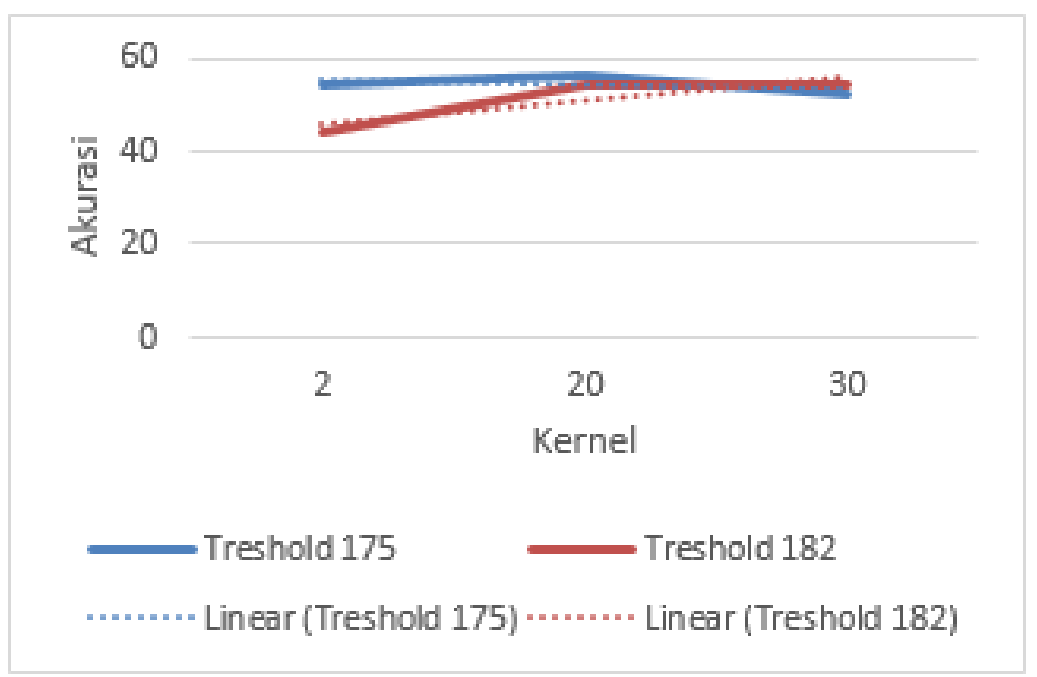

Gambar 8. Grafik hubungan kernel, akurasi, dan threshold

Berdasarkan grafik diatas, akurasi threshold 175 akan lebih baik dengan menggunakan kernel dibawah 20.

\subsection{Waktu Komputasi}

Berdasarkan grafik regresi linear diatas, efisiensi kerja terbaik ada pada saat menggunakan template lama dengan threshold 175, kernel 2, dengan akurasi 60\% dan waktu komputasi $1.37 \mathrm{~s}$. Namun sistem lebih dititik-beratkan dalam akurasi deteksi. Dengan akurasi deteksi mencapai $76 \%$, sistem hanya membutuhkan waktu rata-rata $1.51 \mathrm{~s}$ untuk mendeteksi glaukoma. 


\section{KESIMPULAN}

Dari hasil simulasi dan analisis dapat diambil beberapa kesimpulan:

1. Nilai threshold dan ukuran kernel mempengaruhi akurasi dan waktu komputasi. Semakin besar nilai kernel, semakin besar juga waktu yang digunakan untuk komputasi. Sementara nilai threshold terhadap waktu komputasi berubah fluktuatif, tergantung template yang digunakan.

2. Deteksi penyakit glukoma melalui pengolahan citra fundus dengan menghitung luas optik disk dapat dilakukan dengan tingkat akurasi sebesar 76\%. Tingkat akurasi ini dinilai belum tinggi dikarenakan terdapat distorsi citra saat proses deteksi tepi optik disk sehingga didapatkan ukuran optik disk yang tidak sesuai dengan yang sebenarnya

3. Template baru memiliki akurasi yang lebih rendah baik dalam deteksi optik disk maupun deteksi glaukoma. Template lama memiliki akurasi sebesar 93\% dalam mendeteksi optik disk, dengan template baru yang hanya memiliki akurasi sebesar $81 \%$. Namun performa template merah lebih baik pada foto fundus digital dengan kecerahan yang lebih tinggi.

\section{Daftar Pustaka:}

[1] H. A. Quigley dan A. T. Broman, "The number of people with glaucoma worldwide in 2010 and 2020," Br J Ophthalmol, vol. 90(3), pp. 262-267, 2006.

[2] Singapore National Eye Centre, "SNEC," Eye Center, [Online]. Available: http://www.snec.com.sg/about/international/menuutama/kondisimataandperawatan/commo n-problems/Pages/Glaucoma.aspx. [Diakses 5 Desember 2014]

[3] D. Pascolini dan S. Mariotti, "Global estimates of visual impairment: 2010," $\mathrm{Br} J$ Ophthalmol, vol. 96(5), pp. 614-618, 2012.

[4] H. A. Quigley, "Glaucoma: What Every Patient Should Know," Johns Hopkins Medicine, 2011.

[5] J. Nayak, R. A. U., P. S. Bhat, N. Shetty dan T.-C. Lim, "Automated Diagnosis of Glaucoma Using Digital Fundus Images,” J Med Syst, vol. 33, pp. 337-346, 2009.

[6] A. Pachiyappan, U. N. Das, T. V.S.P. Murthy dan R. Tatavarti, "Automated diagnosis of diabetic retinopathy and glaucoma using fundus and OCT image," Lipids in Health abd Disease, 2012.

[7] Zahara, H.S., "Simulasi Untuk Klasifikasi Retinopati Diabetes Non-proliferatif Berdasarkan Mikroaneurisma dan Hemorrhages”, Institut Teknologi Telkom, 2011.

[8] H. Kolb, "How the Retina Works," American Scientist, 2003.

[9] S. M. B., Shields Textbook of Glaucoma. 4th ed., New York: Lippincott Williams and Wilkins, 2005.

[10] National Eye Institute, "NEI," Eye Center, [Online]. Available: https://www.nei.nih.gov/health/glaucoma/glaucoma_facts.asp\#a. [Diakses 10 Desember 2014]

[11] P. J. Saine dan M. E. Tyler, Ophthalmic Photography: Retinal Photography, Angiography, and Electronic Imaging, 2nd Edition, Butterworth-Heinemann Medical

[12] Munir, R., "Pengolahan Citra Digital", Bandung, 2004.

[13] Hestiningsih, I, "Pengolahan Citra".

[14] Brunelli, R., "Template Matching Techniques in Computer Vision: Theory and Practices", John Wiley \& Sons, Ltd., ISBN: 978-0-470-51706-2, 2009.

[15] Smith, S. W., "Digital Signal Processing: A Practical Guide for Engineers and Scientists", ISBN: 0-7506-7444-X 